\title{
Atmospheric Radiation Measurement Program Climate Research Facility Operations Quarterly Report
}

January 1 - March 31, 2005

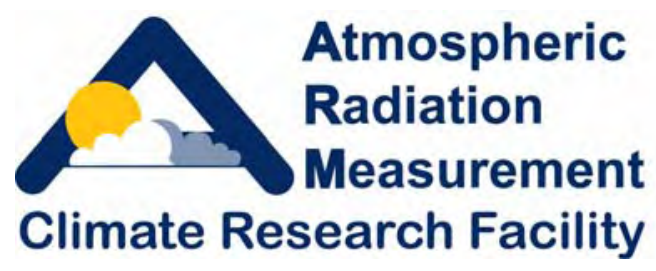

Work supported by the U.S. Department of Energy, Office of Science, Office of Biological and Environmental Research 


\section{Contents}

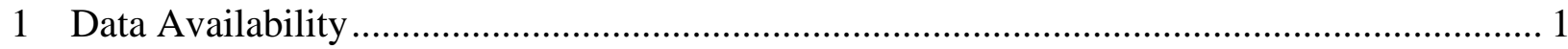

2 Site Visit Requests, Archive Accounts, and Research Computer Accounts........................... 2

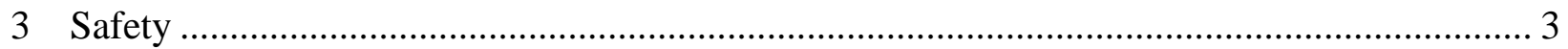

\section{Tables}

1 Operational Statistics for the Fixed ACRF Sites for the Period January 1 -

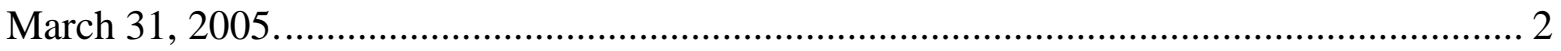

2 Operational Statistics for the ARM Mobile Facility for the Period January 1 March 31, 2005..................................................................................................... 2

3 Summary of ACRF User Site Visits, Archive Accounts, and Research Computer Accounts for the April 1, 2004 - March 31, 2005......................................................... 3

4 Consecutive Days Since Last Recordable Lost Time Incident or Property Damage Incident, January 1-March 31, 2005.............................................................................. 4 


\section{Atmospheric Radiation Measurement Program Climate Research Facility Operations Quarterly Report January 1 - March 31, 2005}

\section{Data Availability}

Description. Individual raw data streams from instrumentation at the Atmospheric Radiation Measurement (ARM) Program Climate Research Facility (ACRF) fixed and mobile sites are collected and sent to the Data Management Facility (DMF) at Pacific Northwest National Laboratory for processing in near real time. Raw and processed data are then sent daily to the ACRF Archive, where they are made available to users. For each instrument, we calculate the ratio of the actual number of data records received daily at the Archive to the expected number of data records. The results are tabulated by (1) individual data stream, site, and month for the current year and (2) site and fiscal year dating back to 1998.

The United States Department of Energy requires national user facilities to report time-based operating data. The requirements concern the actual hours of operation (ACTUAL); the estimated maximum operation or uptime goal (OPSMAX), which accounts for planned downtime; and the VARIANCE [1 - (ACTUAL/OPSMAX)], which accounts for unplanned downtime. The OPSMAX time for this second quarter for the Southern Great Plains (SGP) site is 2052 hours $(0.95 \times 2,160$ hours this quarter). The annual OPSMAX for the North Slope Alaska (NSA) site is 1944 hours $(0.90 \times 2,160)$, and that for the Tropical Western Pacific (TWP) site is 1836 hours $(0.85 \times 2,160)$. The differences in OPSMAX performance reflect the complexity of local logistics and the frequency of extreme weather events. It is impractical to measure OPSMAX for each instrument or data stream. Data availability reported here refers to the average of the individual, continuous data streams that have been received by the ACRF Archive. Data not at the Archive are caused by downtime (scheduled or unplanned) of the individual instruments. Therefore, data availability is directly related to individual instrument uptime. Thus, the average percent of data in the Archive represents the average percent of the time (24 hours per day, 90 days for this quarter) the instruments were operating this quarter.

In addition, the ARM Mobile Facility (AMF) made its debut on March 15 at Point Reyes, California, in support of the MArine Stratus Radiation Aerosol and Drizzle (MASRAD) field experiment, to be conducted March 15 - September 15, 2005. The OPSMAX for the AMF is 387.6 hours ( $0.95 \times 408$ hours this quarter).

Summary. Table 1 shows the accumulated maximum operation time (planned uptime), the actual hours of operation, and the variance (unplanned downtime) for the period January 1 through March 31, 2005, for the fixed sites, and Table 2 shows the information for the ARM Mobile Facility. The second quarter comprises a total of 2,160 hours. For all fixed and mobile 
sites, the actual data availability (and therefore actual hours of operation) met or slightly exceeded the operational goal for the second quarter of Fiscal Year (FY) 2005.

Table 1. Operational Statistics for the Fixed ACRF Sites for the Period January 1 March 31, 2005.

\begin{tabular}{|c|c|c|c|c|c|}
\hline & \multicolumn{3}{|c|}{ Hours Of Operation } & \multicolumn{2}{c|}{ Data Availability } \\
\hline Site & Opsmax & Actual & Variance & Goal & Actual \\
\hline NSA & $1,944.00$ & $1,972.73$ & -0.015 & 0.90 & 0.91 \\
\hline SGP & $2,052.00$ & $2,052.00$ & -0.000 & 0.95 & 0.95 \\
\hline TWP & $1,836.00$ & $1,936.87$ & -0.055 & 0.85 & 0.90 \\
\hline Site Average & $\mathbf{1 , 9 4 4 . 0 0}$ & $\mathbf{1 , 9 8 7 . 2 0}$ & $\mathbf{- 0 . 0 2 2}$ & $\mathbf{0 . 9 0}$ & $\mathbf{0 . 9 2}$ \\
\hline
\end{tabular}

Table 2. Operational Statistics for the ARM Mobile Facility for the Period January 1 March 31, 2005.

\begin{tabular}{|c|c|c|c|c|c|}
\hline & \multicolumn{3}{|c|}{ Hours Of Operation } & \multicolumn{2}{c|}{ Data Availability } \\
\hline Site & Opsmax & Actual & Variance & Goal & Actual \\
\hline AMF & 387.60 & 391.68 & -0.011 & 0.95 & 0.96 \\
\hline
\end{tabular}

\section{Site Visit Requests, Archive Accounts, and Research Computer Accounts}

Description. The Site Access Request System is a web-based database used to track visitors to the fixed sites, all of which have facilities that can be visited. The NSA site has the Barrow and Atqasuk facilities. The SGP site has 1 central facility, 23 extended facilities, 4 boundary facilities, and 3 intermediate facilities. The TWP site has the Manus, Nauru, and Darwin facilities. In addition, users who require data more timely than that provided by the ACRF Archive can request an account on the local site data system. The 7 research computers are located at the Barrow and Atqasuk facilities; the SGP central facility; the TWP Manus, Nauru, and Darwin facilities; and the DMF at Pacific Northwest National Laboratory. This report provides the cumulative numbers of visitors and user accounts by site for the period April 1, 2004 through March 31, 2005.

The United States Department of Energy requires national user facilities to report facility use by total visitor days - broken down by institution type, gender, race, citizenship, visitor role, visit purpose, and facility - for actual visitors and for active user research computer accounts. During this reporting period, the ACRF Archive did not collect data on user characteristics in this way. Work is under way to collect and report these data. 
Research computer accounts are counted in the same manner as for the ACRF Archive accounts: an individual is counted as only one unique user per site, even though he or she opens and closes an account several times to obtain different data at one or more sites. However, site visitors are counted each time they visit, because many visitors participate in multiple, unrelated experiments or events.

Also, users that visit sites can also connect their computer or instrument to an ACRF network, which requires an on-site device account. Remote (off-site) users can also have remote access to any ACRF instrument or computer system at any ACRF site, which requires an off-site device account. These accounts are also tracked.

All user accounts are established for period of up to one year and must be renewed annually. To report users, we counted the number of active users for the previous 12 months during the last month of the quarterly reporting period.

Summary. Table 3 shows the summary of cumulative users through the second quarter of FY 2005. For the period April 1, 2004 -March 31, 2005, the NSA site had a large number of visitors before and during the Mixed-Phase Arctic Cloud Experiment intensive operational period (IOP). This was expected, since the ARM Program has put a high priority on NSA activities. Likewise, we expect the numbers of users of the ARM Mobile Facility to grow during its deployment at Point Reyes, California.

Table 3. Summary of ACRF User Site Visits, Archive Accounts, and Research Computer Accounts for the April 1, 2004 - March 31, 2005.

\begin{tabular}{|l|c|c|c|c|c|c|c|}
\hline \multicolumn{1}{|c|}{ Site } & Visitors & $\begin{array}{c}\text { Visitor } \\
\text { Days }\end{array}$ & $\begin{array}{c}\text { On-Site } \\
\text { Device } \\
\text { Accounts }\end{array}$ & $\begin{array}{c}\text { Off-Site } \\
\text { Device } \\
\text { Accounts }\end{array}$ & $\begin{array}{c}\text { Research } \\
\text { Accounts }\end{array}$ & $\begin{array}{c}\text { Archive } \\
\text { Accounts }\end{array}$ & $\begin{array}{c}\text { Total } \\
\text { Users }\end{array}$ \\
\hline NSA & 155 & 1,332 & 25 & 18 & 35 & 176 & $\mathbf{4 0 9}$ \\
\hline SGP & 146 & 602 & 18 & 15 & 33 & 489 & $\mathbf{7 0 1}$ \\
\hline TWP & 110 & 399 & 4 & 13 & 22 & 162 & 311 \\
\hline AMF & 36 & 213 & 3 & 7 & 5 & 1 & $\mathbf{5 2}$ \\
\hline DMF & & & & & 24 & & $\mathbf{2 4}$ \\
\hline Total & 447 & 2,546 & 50 & 53 & 119 & 828 & $\mathbf{1 , 4 9 7}$ \\
\hline
\end{tabular}

\section{Safety}

For reporting purposes, the three ACRF Sites and ARM Mobile Facility operate 24 hours per day, 7 days per week, 52 weeks per year. Time is reported in days instead of hours. Although the ARM Mobile Facility was officially deployed in Point Reyes, California, on March 15, 2005, safety statistics are included during the assembly and testing period of the facility, as well. If any lost work time is incurred by any employee, it is counted as a workday loss. Consecutive 
days since the last recordable or reportable injury or by damage to property, equipment, or vehicle are provided in Table 4 for the period January 1 - March 31, 2005. There were no lost days for the second quarter of FY 2005.

Table 4. Consecutive Days Since Last Recordable Lost Time Incident or Property Damage Incident, January 1-March 31, 2005.

\begin{tabular}{|l|c|c|c|c|}
\hline \multicolumn{1}{|c|}{ ES\&H Category } & NSA & SGP & TWP & $\begin{array}{c}\text { ARM } \\
\text { Mobile } \\
\text { Facility }\end{array}$ \\
\hline Days Worked without a Lost Time Incident & 90 & 90 & 90 & 90 \\
\hline Days Worked without a Recordable Accident (Doctor Case) & 90 & 90 & 90 & 90 \\
\hline $\begin{array}{l}\text { Days Worked without a Recordable Incident (Property- } \\
\text { Equipment Damage/Loss) }\end{array}$ & 90 & 90 & 90 & 90 \\
\hline Days Worked without a Reportable Loss to Vehicles & 90 & 90 & 90 & 90 \\
\hline
\end{tabular}

